\title{
Cisplatin/Cyclophosphamide/Estramustine/Fluorourá Regimen
}

National Cancer Institute

\section{Source}

National Cancer Institute. Cisplatin/Cyclophosphamide/Estramustine/Fluorouracil

Regimen. NCl Thesaurus. Code C161940.

A chemotherapy regimen consisting of cisplatin, cyclophosphamide, fluorouracil, and estramustine that may be used in the treatment of prostate cancer. 